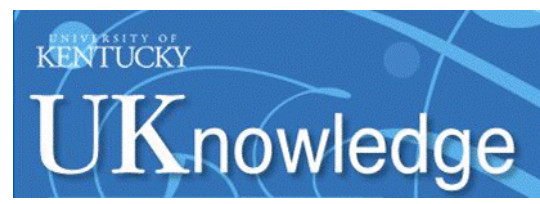

University of Kentucky

UKnowledge

\title{
Menstrual Bleeding Patterns in Adolescents Using Etonogestrel (ENG) Implant
}

\author{
Amit M. Deokar \\ University of Kentucky \\ Wendy Jackson \\ University of Kentucky, wnelson@uky.edu \\ Hatim A. Omar \\ University of Kentucky, hatim.omar@uky.edu
}

Follow this and additional works at: https://uknowledge.uky.edu/pediatrics_facpub

Part of the Obstetrics and Gynecology Commons, and the Pediatrics Commons

Right click to open a feedback form in a new tab to let us know how this document benefits you.

\section{Repository Citation}

Deokar, Amit M.; Jackson, Wendy; and Omar, Hatim A., "Menstrual Bleeding Patterns in Adolescents Using Etonogestrel (ENG) Implant" (2011). Pediatrics Faculty Publications. 244.

https://uknowledge.uky.edu/pediatrics_facpub/244

This Article is brought to you for free and open access by the Pediatrics at UKnowledge. It has been accepted for inclusion in Pediatrics Faculty Publications by an authorized administrator of UKnowledge. For more information, please contact UKnowledge@lsv.uky.edu. 


\section{Menstrual Bleeding Patterns in Adolescents Using Etonogestrel (ENG) Implant \\ Digital Object Identifier (DOI) \\ https://doi.org/10.1515/ijamh.2011.013}

\section{Notes/Citation Information}

Published in International Journal of Adolescent Medicine and Health, v. 23, issue 1, p. 75-77.

(๑ 2011 by Walter de Gruyter Berlin Boston

The copyright holder has granted permission for posting the article here. 


\section{Menstrual bleeding patterns in adolescents using etonogestrel (ENG) implant}

\author{
Amit M. Deokar, Wendy Jackson and Hatim A. Omar* \\ Department of Pediatrics, Division of Adolescent \\ Medicine and Department of Obstetrics and Gynecology, \\ Kentucky Women's Health, University of Kentucky, \\ Lexington, KY, USA
}

\begin{abstract}
Background: Etonogestrel (ENG) implant is an effective method of contraception. The implant is designed to provide contraceptive efficacy for 3 years with a relatively quick return of fertility upon its removal. Menstrual irregularities are not uncommon on long-acting progestins and can often be the factor for discontinuation or removal. A retrospective chart analysis was done on 58 patients who chose to be on the ENG implant. Age ranged from 12 to 24 years. The cycle ranged from 1 to 17 months. The mean length of use of the implant was 10.9 months. Over the 20 -month period, 13 ENG implants were removed because of menstrual bleeding problems.

Method: We conducted a chart review of the adolescent patients who received the ENG implant in our adolescent clinic. An analysis was done based on symptoms experienced by patients who were on the ENG implant and their management, which in some cases resulted in its removal.

Setting: The data is presented on adolescent and young adult patients who receive their reproductive care in the Adolescent Medicine Clinic at the University of Kentucky, Lexington, KY, USA.

Conclusions: ENG implant when used correctly and as indicated is extremely effective in providing contraception for up to 3 years. However, menstrual irregularities can be very troublesome and often a reason for its removal. In our experience, $22.4 \%$ (13 out of the 58 subjects) had menstrual problems post-insertion that led to its removal. It is crucial for a clinician to inform and be informed about such side effects.
\end{abstract}

Keywords: adolescents; contraceptives; depot medroxyprogesterone acetate; doxycycline; ethinyl estradiol; etonogestrel (ENG); mifepristone; progesterone/progestin.

\footnotetext{
*Corresponding author: Professor Hatim A. Omar, MD, FAAP, Director of Adolescent Medicine and Young Parent Programs, J422 Kentucky Clinic, Department of Pediatrics, Kentucky Children's Hospital, University of Kentucky College of Medicine, Lexington, KY 40536, USA

Phone: +1-859-323-6426 ext. 311, Fax: +1-859-257-7706,

E-mail: haomar2@uky.edu

Submitted June 20, 2010. Revised August 25, 2010. Accepted

September 8, 2010. Previously published online March 1, 2011.
}

\section{Introduction}

There are more than 20 million women worldwide who use long-acting progesterone-only contraceptives $(1,2)$. These are extremely effective contraceptives with a failure rate of $0.3 \%-1.0 \%$ annually (2). Etonogestrel (ENG) implant marketed as Implanon ${ }^{\text {TM }}$ is a progestin-only subdermal contraceptive implant that was first marketed in Indonesia in 1998 (3, 4). Since then, more than 3 million implants have been dispensed throughout the world. It was first approved in the US by the Food and Drug Administration (FDA) in 2006 (3, 5). It consists of a sterile non-biodegradable single rod implant (dimension: $4 \mathrm{~cm} \times 2 \mathrm{~mm}$ ) that contains $68 \mathrm{mg}$ of the biologically active metabolite of Desogestrel called Etonogestrel (ENG) (1, 3-5). There is a gradual decline in the hormone released from approximately $60-70 \mu \mathrm{g} /$ day following a few weeks after its insertion to approximately $25-30 \mu \mathrm{g}$ by the end of 3 years (4, $6,7)$. Some important features of the implant are as follows: (i) mechanism of action of the ENG implant; (ii) one of the most common reasons for its discontinuation, i.e., menstrual irregularities; and (iii) data from the chart review of patients in our clinic who experienced menstrual irregularities.

The contraceptive mechanisms of the ENG implant are as follows $(4,6,7)$ : (a) suppression of luteinizing hormone surge (although the follicle stimulating hormone is also suppressed, but only partially); (b) increased viscosity of the cervical mucus that impedes sperm penetration; and (c) alteration (thinning) of the endometrium.

At present, clinicians are required to undergo training conducted by Organon (manufacturer) before they can insert the Implanon $^{\mathrm{TM}}$ in a patient. Within 1-2 weeks of removal of the Implanon $^{\mathrm{TM}}$, fertility is reversed $(6,8)$. There are some other key clinical features of Implanon ${ }^{\mathrm{TM}}$ that a clinician needs to be aware of and are listed below $(4,7,9)$.

1. For a patient who seeks a long-acting progesterone implant, the clinician must provide adequate pre- and post-insertion counseling. This is very crucial because menstrual abnormalities continue to be the most common reason for discontinuation and removal of the implant. Even though data might be inconclusive on progesterone directly increasing the risk of thrombosis, women should still be counseled to refrain from tobacco smoke.

2. Informed consent must be obtained before the insertion, removal or replacement. It is of utmost importance for the patient to know that Implanon ${ }^{\mathrm{TM}}$ does not prevent sexually transmitted infections, and appropriate measures must be taken to prevent such infections.

3. During its clinical trials, Implanon ${ }^{\mathrm{TM}}$ was not studied in women who weighed more than $130 \%$ of their ideal body weight. The serum concentration of ENG is inversely 
proportional to the body weight and the length of time for which the implant was in place.

4. Over the course of multiple years, the ENG implant is more cost-effective than combined oral contraceptives.

5. Unintended pregnancies in the first year of the Implanon ${ }^{\mathrm{TM}}$ use are estimated to be $<0.05 \%$ ( 1 in 100 users).

6. As a result of drug interactions, plasma levels of ENG can vary especially if the patient is on medications that induce or inhibit the hepatic enzymes.

7. When compared to depot medroxyprogesterone acetate, the effect of Implanon ${ }^{\mathrm{TM}}$ on bone mineral density (BMD) is reassuring. In contrast, pregnancy and lactation have relatively worse effects on bone density. BMD usually returns to baseline within a few years of stopping the long-acting progesterone containing contraceptives.

\section{Side effects}

Contraceptives containing long-acting progesterone are invaluable in preventing teen pregnancy. Implanon ${ }^{\mathrm{TM}}$ is a good example of one such contraceptive. All hormonal contraceptives have a certain side-effect profile, including the ENG implant. This article focuses on menstrual irregularities and problems associated with its use and how they can influence patients desire to opt for its discontinuation/removal.

There are varying patterns of menstrual abnormalities that are possible with Implanon ${ }^{\mathrm{TM}}$ use. These include amenorrhea, prolonged and heavy bleeding, irregular bleeding, spotting, and an unpredictable bleeding pattern, etc. $(1,3,4,7)$. The most frequent reason reported by women is unpredictable and irregular vaginal bleeding. In Implanon ${ }^{\mathrm{TM}}$ users, the bleeding pattern is most likely to vary in the first 3 months after insertion (6). This can lead to frustration and poor quality of life. These issues can cause anxiety and discontent in the teenager's mind. It is advisable to keep a menstrual diary that will help the clinician to manage the menstrual problems effectively.

There are several reasons cited that play a role in the bleeding irregularities in progesterone users. These include altered endometrial matrix metalloproteinase (MMP), vascular fragility, irregular endometrial blood vessels, decreased glandular and stromal support, and decreased integrity of the epithelium $(1,10)$. According to Weisberg et al. (1) and Monsour et al. (11), a review of 11 clinical trials involving Implanon ${ }^{\text {TM }}$ $(n=923)$ revealed that $11.3 \%$ of the users discontinued it because of prolonged and frequent menstrual bleeding $(1,11)$. Differences in culture, personal and social factors, and tolerance to bleeding irregularities can largely affect one's decision to discontinue with Implanon ${ }^{\mathrm{TM}}(6)$.

\section{Chart review}

From February 2008 to October 2009, a total number of 58 patients received Implanon ${ }^{\mathrm{TM}}$, which was placed by certified and trained clinicians in the Division of Adolescent Medicine, University of Kentucky, Lexington, KY, USA. The age range of the patients was between 12 and 24 years. The maximum number days the patients retained their Implanon ${ }^{\text {TM }}$ post-insertion varied from 26 days to 17 months before they were electively discontinued and removed. Out of the 58 patients, $13(22.4 \%)$ requested removal and discontinuation of Implanon ${ }^{\mathrm{TM}}$ primarily because of menstrual irregularities.

The menstrual problems ranged from spotting to an overt period. The duration of bleeding post-ENG implant was categorized into 1-7 days and continuous (more than 7 days and multiple breakthrough bleeding episodes). The management of such bleeding patterns included use of combination contraceptive pills to removal of the implant. Based on our data, this is one of the highest percentages of patients opting for its discontinuation and removal.

\section{Management of menstrual irregularities}

A variety of treatment options are available for menstrual irregularities associated with Implanon ${ }^{\mathrm{TM}}$ use. Some are more effective than others and thus need to be patient-specific (1, 7). It is crucial to not use any of these recommendations in undiagnosed vaginal bleeding.

- Doxycycline $100 \mathrm{mg}$ twice daily for 5 days. The inhibition of MMP mediated degeneration of the endometrial matrix is believed to be the mechanism of its action.

- Mifepristone $(25 \mathrm{mg}$ ) twice for 1 day followed by ethinyl estradiol (EE) $10 \mu \mathrm{g}$ twice a day for 4 days. Such a regimen depends on the availability of mifepristone and that there are no contraindications for its use along with EE. Mifepristone works by stabilizing the endometrium by its rapid repair action.

- Combination oral contraceptives. The dose and duration is a matter of the clinician's preference and patient's tolerability.

- Non-streroidal anti-inflammatory drugs (NSAIDs). An example is high dose of ibuprofen ( $800 \mathrm{mg}$ three times a day) or mefenamic acid (500 mg three times a day) for 5 days. NSAIDs act by blocking the prostaglandin synthesis. Platelet aggregation and endometrial vasoconstriction can also play a crucial role.

\section{Conclusion}

Long-acting progesterone contraceptives are extremely effective in preventing teen pregnancies. Some contraceptives such as Implanon ${ }^{\mathrm{TM}}$ also allow relatively quick return of fertility. They can be very cost-effective when used over multiple years. However, menstrual irregularities and problems are some of the major reasons for its discontinuation and removal. Therefore, it is very important for the clinician to provide the patient with adequate pre-, post-insertion, and pre-removal counseling so that an educated decision can be facilitated.

There are patient specific recommendations to manage the bleeding irregularities and include a choice of doxycycline, EE, mifepristone, combination oral contraceptives, 
and NSAIDs. Patients who discontinue Implanon ${ }^{\mathrm{TM}}$ should be given an alternate contraceptive recommendation to prevent an unintended pregnancy.

\section{References}

1. Weisberg E, Hickey M, Palmer D, Connor O, Samalonsen LA, Findlay JK, Fraser IS. A randomized controlled trial of treatment options for troublesome uterine bleeding in implanon user. Hum Reprod 2009;24:1852-61.

2. d'Arcangues C. Management of vaginal bleeding irregularities induced by progestin-only contraceptive. Human Reprod 2000; 3:24-9.

3. Darney P, Patel A, Rosen K, Shapiro LS, Kaunitz AM. Safety and efficacy of a single-rod etonogestrel implant (Implanon): results from 11 international clinical trials. Fertil Steril 2009; 91:1646-61.
4. Implanon website. Welcome to implanon for health professionals. Accessed May 20, 2010. Available at: www.implnon-usa. com/index.asp?svarqvp2=0.

5. Tolaymat LL, Kaunitz AM. Long-acting contraceptives in adolescents. Curr Opin Obstet Gynecol 2007;19:453-60.

6. Fisher M. Implanon: a new contraceptive implant. J Obstet Gynecol Neonatal Nurs 2008;37:361-8.

7. Adams K, Beal MW. Implanon: a review of the literature with recommendations for clinical management. J Midwifery Womens Health 2009;54:142-9.

8. Huber J. Pharmacokinetics of implanon ${ }^{\circledR}$. An integrated analysis. Contraception 1998;58(Suppl 6):85S-90S.

9. Kaunitz AM. Editorial. Long-acting hormonal contraceptives - indispensable in preventing teen pregnancy. J Adolesc Health 2007;40:1-3.

10. Livinston M, Fraser IS. Mechanism of abnormal uterine bleeding. Hum Reprod Update 2002;8:60-7.

11. Monsour D, Krover T, Marintcheva-Petrova M, Fraser IS. The effects of implanon on menstrual bleeding pattern. Eur $\mathrm{J}$ Contracept Reprod Health Care 2008;13:13-28. 